\title{
Indicators of young women's modern contraceptive use in Burkina Faso and Mali from Demographic and Health Survey data
}

Amy O'Regan *i] and Gretchen Thompson

\begin{abstract}
Background: High total fertility rates in Burkina Faso and Mali are leading to population growth beyond the agricultural and fiscal means of its citizens. Providing access to affordable family planning methods is a key step in driving the demographic transition where fertility and mortality rates decline. Furthermore, both nations face significant challenges as climate change is projected to disproportionately impact the western Sahel region undermining environmental, social and economic stability within the region. This analysis was included in formative research to inform family planning programming. The aim of this study was to examine possible indicators of long acting and permanent contraceptive method (LAPM) and short-term method (STM) use for young women in Burkina Faso and Mali.

Methods: Secondary data analysis was conducted using the three most recent Demographic and Health Survey (DHS) datasets for Burkina Faso $(1998,2003,2010)$ and Mali $(2001,2006,2012)$. Women ages 15-24, at risk for unwanted pregnancy were included in these analyses. Summary descriptive statistics across all time points are reported and multinomial logistic regression was used with the most recent data to determine potential indicators of different types of modern contraceptive methods.
\end{abstract}

Results: In Burkina Faso in 2010, 24\% of women ages 15-24 were using modern contraceptives. Only 2.9\% reported using LAPMs in 2010, an increase from 0.3\% in 1998. In Mali, modern contraceptive use increased more recently, rising from 9.4\% in 2001 to $10.2 \%$ in 2006 to 15.3\% in 2012. LAPM use also increased from 0.3\% in 2001 to $4.1 \%$ in 2012. Significant indicators of LAPM contraceptive use in both countries included educational attainment, ideal family size, home ownership and husband's desire for more children.

Conclusions: Young women in Burkina Faso and Mali are increasingly using modern contraceptives for family planning; however, the LAPM contraceptive prevalence rate remains low. Our analysis indicates that social norms around ideal family size for both men and women continue to drive young women's choices around family planning and impede use of LAPMs. To increase modern contraceptive use and curb fertility rates, local governments and development organizations should focus on women's empowerment and include male partners.

Keywords: Contraceptives, Burkina Faso, Mali, Adolescents

* Correspondence: AORegan@fhi360.org

FHI 360, 359 Blackwell St. Suite 200, Durham, NC, USA 


\section{Background}

If current projections hold true, the population of Sub-Saharan Africa will more than double in the next 36 years. [1] These significant population increases are particularly apparent in the Sahel region of Africa where the Sahara Desert meets the Savannah plains. Countries in this arid, rural region, have some of the highest total fertility rates (TFR) in the world, ranging from 4.1 in Mauritania to 7.6 in Niger in 2014 [2]. A rapidly increasing population is particularly troubling for this region, where the impact of climate change on agricultural production has already led to substantial food insecurity and is expected to worsen in the future. [1] Maternal, child and neonatal mortality rates in this region rank as some of the highest in the world [2], contributing to a vast number of preventable deaths. Providing access to affordable family planning methods is a key step in driving countries toward a demographic transition where fertility and mortality rates decline. [1]

Although there has been an increase in family planning and contraceptive use over the last few decades, the number of women using modern contraceptives remains low in many countries in the Sahel, contributing to high fertility rates. In Mali, the national TFR was 6.1 in 2014 [2]. In Burkina Faso, it was only slightly lower at 5.9 [2]. High fertility rates can have a devastating impact on women's health, including increased maternal mortality, birth complications, and unsafe abortions. [3]

Young women in the Sahel likely face significant barriers to accessing family planning methods. Poor health infrastructure, lack of trained providers and contraceptive commodities, financial barriers, and community opposition to family planning can all impede access to modern contraceptives. [4] Prior research shows that wealth can contribute to significant inequities in access and uptake of long-acting and permanent method (LAPM) contraceptives [5], but these studies have not included messaging exposure, sexual and reproductive health indicators, or normative indicators that drive family size and fertility choices. Also, structural and cultural barriers to effective contraceptive use may also be exacerbated for adolescents living in rural areas, and limitations may be particularly acute for those who are unmarried and/or nulliparous.

This paper presents an analysis of Demographic and Health Survey (DHS) data from Burkina Faso and Mali. This analysis was included in formative research to inform family planning programming. The aim of this study was to examine possible indicators of LAPM and short-term method (STM) use for young, sexually active women in Burkina Faso and Mali. We used a range of indicators including personal sexual behavior often missing from determinants of contraceptive use studies [6]. These findings may be used to influence future programming for young women in these countries targeted at increasing LAPM contraceptive uptake.

\section{Methods \\ Data sources}

Secondary analysis was conducted using women's survey data from the DHS for Burkina Faso (1998, 2003, 2010) and Mali (2001, 2006, 2012). Two-stage cluster sampling methods were used to collect data for all countries and time points. Detailed descriptions of sampling methods are described in each of the DHS final reports. [7] The data were weighted to adjust for sampling design and non-response.

\section{Study design}

This study employs a four-tiered approach to examine indicators of LAPM and STM among young women in Burkina Faso and Mali.

1. To measure frequencies and observe trends in contraceptive use and potential indicators, we conducted summary descriptive analysis of women's survey data from the three most recent DHS for Burkina Faso (1998, 2003, 2010) and Mali (2001, 2006, 2012).

2. Variables were selected for model inclusion based on relevance in the peer-reviewed literature and pared down based on a bivariate correlation analysis and preliminary significance testing (detailed below) to limit the number of co-variates in the model to meet the degrees of freedom threshold required to perform multinomial modeling.

3. Using the most recent data for each country, binomial logistic regression procedures were performed to identify indicators of modern contraceptive use for both married and unmarried women and inform variable inclusion for multinomial models.

4. Using the most recent data for Burkina Faso and Mali, multinomial logistic regression procedures were performed to identify indicators of LAPM and STM for all women and married women.

\section{Variables}

Two primary outcomes were created to describe current contraceptive use. The first binary outcome classifies current contraceptive use as modern methods vs. traditional methods or nonusers. This outcome was used in initial significance testing. For the purposes of these analyses, modern contraceptives include: intra-uterine device (IUD), implant, pill, injection, male sterilization, condom, diaphragm, female condom, foam, or jelly. The second multinomial regression analysis used a threecategory outcome variable. Outcome categories were (1) 
LAPM, which classifies current contraceptive use as long-acting or permanent methods (IUD, implant, male sterilization) vs. (2) short-term modern methods (pill, injection, condom, diaphragm, female condom, foam, or jelly) vs. (3 - reference category) traditional or nonusers.

Variables describing sexual and reproductive health (SRH) behaviors, access to care, contraceptive knowledge, contraceptive use, and fertility intentions were described across all datasets in which indicators were available. Selected variables are listed in Table 1. Frequencies, weighted percentages, means, and 95\% confidence intervals were calculated for all variables and are

Table 1 Independent variables considered for multivariate model inclusion

\begin{tabular}{|c|c|}
\hline Sociodemographic determinants & Access to care \\
\hline Wealth index (standardized) & $\begin{array}{l}\text { Barrier to seeking medical } \\
\text { care: getting permission }\end{array}$ \\
\hline \multicolumn{2}{|l|}{ Age } \\
\hline Educational attainment & $\begin{array}{l}\text { Barrier to seeking medical } \\
\text { care: money }\end{array}$ \\
\hline Residence (urban/rural) & $\begin{array}{l}\text { Barrier to seeking medical } \\
\text { care: distance }\end{array}$ \\
\hline Currently working & $\begin{array}{l}\text { Barrier to seeking medical } \\
\text { care: not wanting to go alone }\end{array}$ \\
\hline Religion & Reproductive Preferences \\
\hline Marital status & $\begin{array}{l}\text { Ever terminated pregnancy } \\
\text { Age at first sex }\end{array}$ \\
\hline Women's empowerment & Number of children \\
\hline Home ownership & Ideal number of children \\
\hline Land ownership & Desire for more children \\
\hline Health care decision making & Total number of wives \\
\hline $\begin{array}{l}\text { Wife beating justified for } \\
\text { refusal to have sex }\end{array}$ & $\begin{array}{l}\text { Age at first marriage/ } \\
\text { cohabitation }^{\mathrm{a}}\end{array}$ \\
\hline $\begin{array}{l}\text { Knowledge and information } \\
\text { on family planning methods }\end{array}$ & Age at first birth \\
\hline $\begin{array}{l}\text { Knowledge of contraceptive } \\
\text { method }^{\mathrm{a}}\end{array}$ & Partner's desire for more children \\
\hline $\begin{array}{l}\text { Heard family planning } \\
\text { messages on radio }\end{array}$ & $\begin{array}{l}\text { Sexual and Reproductive Health } \\
\text { Behavior }\end{array}$ \\
\hline $\begin{array}{l}\text { Saw family planning messages } \\
\text { in newspaper/magazine }\end{array}$ & Sex partners, last 12 months \\
\hline $\begin{array}{l}\text { Saw family planning messages } \\
\text { on TV }\end{array}$ & Sex partners, lifetime \\
\hline $\begin{array}{l}\text { Visited by a family planning health } \\
\text { care worker in the last } 12 \text { months }\end{array}$ & Recent sexual activity \\
\hline \multirow[t]{3}{*}{$\begin{array}{l}\text { Visited a health facility in the } \\
\text { last } 12 \text { months }\end{array}$} & $\begin{array}{l}\text { Contraceptive use and } \\
\text { intention }^{\mathrm{a}}\end{array}$ \\
\hline & $\begin{array}{l}\text { Last source of modern } \\
\text { contraceptive }^{a}\end{array}$ \\
\hline & $\begin{array}{l}\text { Reason for discontinuation of } \\
\text { previous modern method }^{\mathrm{a}}\end{array}$ \\
\hline
\end{tabular}

${ }^{a}$ Variables excluded from regression models due to potential multicollinearity, not enough responses or theoretical redundancy with other indicators. Italicized variables are specific to ever married women or women with children included in an additional file for each country (see Additional files 1 and 2). Response categories for the following variables were collapsed to mitigate the effects of low cell counts during analysis: educational attainment, home ownership, land ownership, religion, marital status, knowledge of contraceptive method, health care decision making, total number of wives, and recent sexual activity. Wealth index, provided by the DHS, was standardized to provide more meaningful interpretations while preserving variability. Standardizing the wealth index was necessary to include wealth as a continuous variable as opposed to one measured ordinally through wealth quintiles.

\section{Data analysis}

Descriptive analysis and primary regression analysis was restricted to women ages 15-24 who were at risk of unwanted pregnancy. Women were excluded from the analysis if they reported never having sex, current pregnancy, wanting a child within two years, postpartum amenorrhea, sterilization or infecundity. Women who had missing values for exclusion categories were considered missing for analysis. A second regression analysis was restricted to married or in union women ages 15-24 who were not currently pregnant. The unweighted sample size for each dataset and sub population is detailed in Table 2.

All data analysis was conducted using SAS Enterprise Guide Version 7.1. Survey procedures were used to account for complex survey design. Weighting, stratification and clustering variables created by the DHS were used throughout analysis. Standard errors were linearized using the Taylor series linearization method to further account for the complex sample design of the DHS. [8]

To limit redundancy in the multivariate models, variables were pared down based on their correlation coefficient, restricting from the models variables correlated 0.8 or higher and thereby reducing multicollinearity. [9] One variable, age at first marriage, was removed using this method as it was highly correlated with age at first sex and age at first birth. Any variables that were directed to women who use modern contraceptives were not added to the models as they would be too highly correlated with the outcome. This final list of variables used for the modelling was separated into six distinct groups used for the initial analyses (see Table 1).

First, to determine which variables would be included in the models, each group of variables (listed above) was modeled to the binary outcome user via logistic regression to determine significance of associations. Using the type three analysis of effects, which measures how much variables contribute to model fit [10], variables were included in subsequent models if they were significant at $p \leq 0.20$. All variables that were significant in the initial analyses were included in the final model for the binary 
Table 2 Unweighted sample size for all datasets and subpopulations

\begin{tabular}{|c|c|c|c|c|c|}
\hline Country & Year & Total sample size & $\begin{array}{l}\text { All women included } \\
\text { in analysis }\end{array}$ & $\begin{array}{l}\text { Married women } \\
\text { included in analysis }^{\mathrm{a}}\end{array}$ & $\begin{array}{l}\text { Excluded from analysis } \\
\text { for missing values }\end{array}$ \\
\hline \multirow[t]{3}{*}{ Burkina Faso } & 2010 & 17,087 & 2826 & 2117 & 34 \\
\hline & 2003 & 12,477 & 2130 & 1505 & 29 \\
\hline & 1998 & 6445 & 1139 & 856 & 5 \\
\hline \multirow[t]{3}{*}{ Mali } & 2012 & 10,424 & 1485 & 1093 & 0 \\
\hline & 2006 & 14,583 & 2313 & 2165 & 88 \\
\hline & 2001 & 12,849 & 2228 & 1750 & 65 \\
\hline
\end{tabular}

${ }^{a}$ Women were excluded from the analysis if they reported never having sex, current pregnancy, wanting a child within two years, postpartum amenorrhea, sterilization or infecundity

outcome user. These analyses were repeated for both countries independently (see Additional file 3). All variables that were significant in the final user model ( $\mathrm{p} \leq 0.20$, type three analysis of effects), were included in the final multinomial logistic regression LAPM model. For all final models, significant variables are reported in Tables 4 and 5 with footnotes listing all insignificant variables included as covariates.

Since some of the variables only applied to married women, the entire multivariate analysis, detailed above, was repeated but restricted to married or in union women. In married women exclusive models, applicable variables (italicized in Table 1) were added to the reproductive preferences and women's empowerment groups and marital status was removed from the sociodemographic determinants group.

\section{Results}

\section{Sample description}

Modern contraceptive use among young women, although still uncommon, increased in both countries over the time period examined. In Burkina Faso in 2010, the modern contraceptive prevalence rate (mCPR) was $23.6 \%$ for women in this sample. Only $2.9 \%$ reported using LAPM in Burkina Faso in 2010, an increase from a meager $0.3 \%$ in 1998 (Fig. 1). In Mali, the mCPR increased more recently, rising from $9.4 \%$ in 2001 to $10.2 \%$ in 2006 to $15.3 \%$ in 2012 . LAPM use also increased from $0.3 \%$ in 2001 to $4.1 \%$ in 2012 (Fig. 1).

Knowledge of a modern family planning method is high in both countries, ranging from $89.5 \%$ in Mali to 97.8\% in Burkina Faso in the most recent DHS data. Age at first sex, first marriage, first birth, and ideal number of children were consistent over the course of the examined time-period. Most young women in this region married and reached sexual debut between the ages of 15 and 16. In both Burkina Faso and Mali, women considered the ideal number of children to be between 5 and 6 . Less than $7 \%$ of women in these populations reported ever having terminated a pregnancy. ${ }^{1}$ Unmet need for family planning was high among this subset of the population in Mali at $49.8 \%$ in 2012, and it had increased from $42.2 \%$ in 2001. Burkina Faso saw a modest decline in unmet need for this subpopulation from $33.8 \%$ in 1998 to $30.9 \%$ in 2010 (Table 3).

\section{Multinomial analysis}

In Burkina Faso, age, home ownership, having two lifetime sex partners, reporting fewer ideal number of children and being sexually active in the last four weeks were significantly associated with the use of LAPM in both models $(p \leq 0.05)$. Being from a rural area, reduced

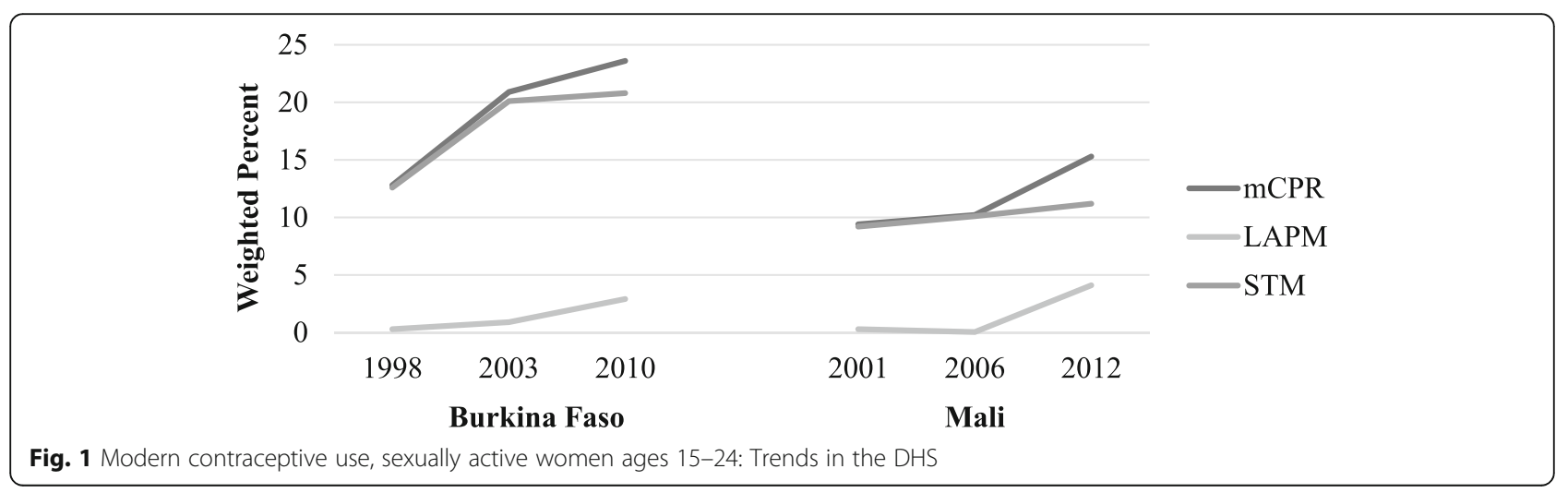


Table 3 Overview of key SRH indicators (weighted percentages and means)

\begin{tabular}{lllllllll}
\hline & \multicolumn{3}{c}{ Burkina Faso } & & & Mali & & \\
\cline { 2 - 3 } & 1998 & 2003 & 2010 & & 2001 & 2006 & 2012 \\
\hline mCPR & 12.8 & 20.9 & 23.6 & & 9.4 & 10.2 & 15.3 \\
LAPM use & 0.3 & 0.9 & 2.9 & & 0.3 & 0.04 & 4.1 \\
STM use & 12.6 & 20.1 & 20.8 & 9.2 & 10.1 & 11.2 \\
Knowledge of modern FP & 79.6 & 92.2 & 97.8 & 81.4 & 81.2 & 89.5 \\
Age at first sex (mean) & 16.1 & 16.4 & 16.5 & 15.2 & 15.4 & 15.5 \\
Age at marriage (mean) & 16.5 & 16.8 & 16.6 & 15.5 & 15.5 & 15.6 \\
Age at first birth (mean) & 17.8 & 18.0 & 18.0 & & 17.0 & 17.0 & 16.8 \\
Ideal no. of children (mean) & 5.3 & 5.0 & 4.9 & & 5.4 & 5.4 & 5.3 \\
Unmet need for FP & 33.8 & 32.2 & 30.9 & & 42.2 & 45.9 & 49.8 \\
Ever terminated pregnancy & $\#$ & 5.4 & 5.3 & & 6.6 & 6.8 & 3.9 \\
\hline
\end{tabular}

\# Question not asked in survey

the odds of LAPM by $80 \%$ compared to being from an urban area $(p \leq 0.05)$. For each additional child the woman reported as the ideal family size, the odds of using LAPM decreased by $20 \%$ for all women and $30 \%$ for married women. Women who reported owning a home, either alone or jointly, had twice the odds of using a LAPM $(p \leq 0.05)$.

Much like LAPM, age, home ownership, lower ideal number of children, having two lifetime sex partners, and being sexually active in the last four weeks were associated with use of STM in both models ( $1 \leq 0.05$ ). In addition, secondary educational attainment was positively associated with use of STM for both models ( $\mathrm{p} \leq 0.05$ ). Completing primary school increased the odds of STM use by $40 \%$ in the inclusive model $(p \leq 0.05)$, but did not remain significant when limited to married women. In both models, the odds of using STM was 30\% less for women who reported that money was a big problem related to getting medical help. The odds of using STM was 2.1 times greater for all nulliparous women and 3 times greater for nulliparous married women, compared to those with children.

Women who were not in union or living with a partner outside of marriage had 1.8 times higher odds of using STMs $(p \leq 0.05)$ compared to married women. In the inclusive model (all women), seeing family planning messaging on TV and having three or more lifetime sex partners was associated with STM use $(p \leq 0.05)$. Women had 50\% lower odds of using STMs if they reported that their husband wanted more children than they did and 40\% lower odds if they did not know how many children their husbands wanted $(p \leq 0.05)$ (Table 4$)$.

In Mali, completing secondary school was significantly associated with both LAPM and STM use $(p \leq 0.05)$. In contrast to the findings in Burkina Faso, women who reported home ownership had lower odds of using STM in both models $(\mathrm{p} \leq 0.05)$. Visiting a health facility in the last 12 months was significantly associated with STM use in both models $(\mathrm{p} \leq 0.05)$. In all models, the odds of using STM or LAPM decreased by $20-30 \%$ as ideal number of children increased. Married women had $80 \%$ lower odds of using an LAPM and 70\% lower odds of using a STM if they reported that their husband wanted more children than they did $(p \leq 0.05)$ (Table 5$)$.

\section{Discussion}

The descriptive analysis of DHS data offers insights into promising trends for the demand and uptake of LAPM and STM contraceptive use among young women throughout Burkina Faso and Mali. Modern contraceptive use, including LAPM, are increasing in both countries, along with knowledge of modern contraceptives. The United Nations predicts that the average mCPR will increase from $17 \%$ in 2015 to $24 \%$ in 2030 in West Africa. [11] Although these trends mean more women will use modern contraceptives, they are still too low to meet the Sustainable Development Goals [12] and it may not have a discernable impact on the TFR.

Our analysis shows that young women are still marrying at early adolescence with very little change over time. Women seem to have their first child within a year of first marriage. The literature suggests this is often because young women must prove their fertility before using any type of hormonal contraceptive [13]. However, our analyses show that nulliparous women had increased odds of using STM in Burkina Faso, however there was no effect on LAPM use. This may indicate that women perceive increased risk of infertility from LAPMs and perceive STMs to be safer. Myths about the safety of hormonal contraceptives for women, and long-acting methods in particular, must be dispelled to provide real family planning options to nulliparous women.

Women in both countries reported high ideal numbers of children, which was a statistically significant indicator in all multinomial models in both countries. We also found that partner's desired family size was significantly associated with contraceptive use. Married young women who reported that their husbands wanted more children than they did had lower odds of using STM in Burkina Faso and both STM and LAPM in Mali. This is consistent with the literature that finds a husband's reproductive preferences is a determinant of reproductive behavior. [14, 15] In both Burkina Faso and Mali, the ideal number of children is high, with women reporting they wanted to have five children on average, and the husband's desire for more children is significantly associated with contraceptive use. Thus, it is reasonable young women would often not be interested in using LAPM, even though they are aware of it. 
Table 4 Burkina Faso 2010: Variables showing evidence of association with LAPM and STM

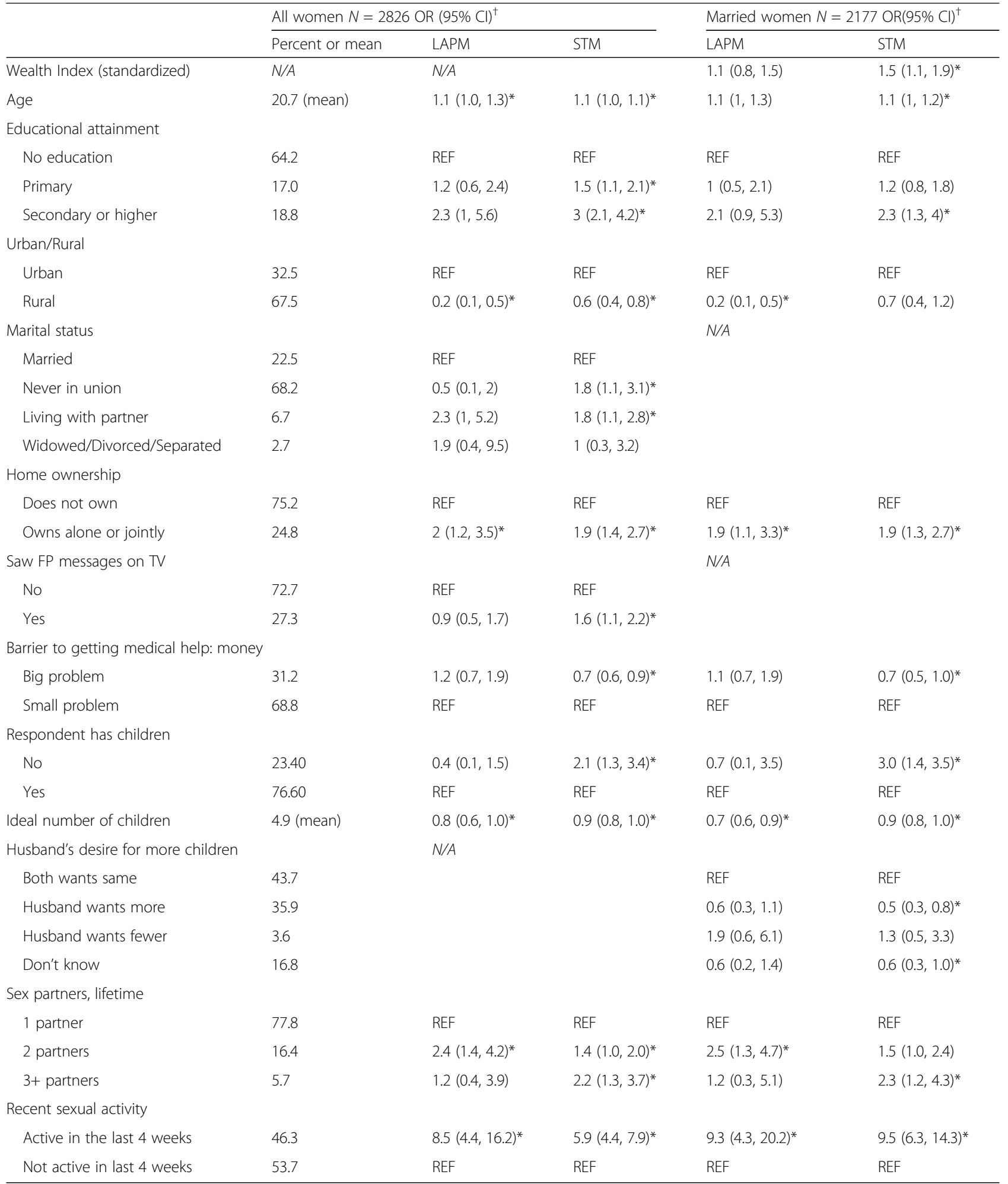

${ }^{\dagger}$ Adjusted for the following variables: currently working, religion, respondent's desire for children. N/A variable not included in model. * $p<0.05$

Similarly, young women who reported home ownership (either alone or jointly) in comparison to not owning a home had higher odds of using STM and
LAPM in Burkina Faso. This may be a proxy for women's empowerment and wealth in the sense that if a woman has real or perceived ownership of her home, 
Table 5 Mali 2012: Variables showing evidence of association with LAPM and STM

\begin{tabular}{|c|c|c|c|c|c|}
\hline & \multicolumn{3}{|c|}{ All women $N=1485$ OR $(95 \% \mathrm{Cl})^{+}$} & \multicolumn{2}{|c|}{ Married women N = 1093 OR $(95 \%$ Cl) } \\
\hline & Percent or mean & LAPM & STM & LAPM & STM \\
\hline Age & 20.0 (mean) & $1.1(1.0,1.3)$ & $1.1(1.0,1.2)$ & $1.3(1.1,1.5)^{*}$ & $1.1(1,1.3)$ \\
\hline \multicolumn{6}{|l|}{ Educational attainment } \\
\hline No education & 59.6 & REF & REF & REF & REF \\
\hline Primary & 11.0 & $1.7(0.7,4.1)$ & $0.7(0.3,1.5)$ & $1.1(0.2,5.2)$ & $1.2(0.5,2.7)$ \\
\hline Secondary & 29.4 & $2.5(1.2,5.4)^{*}$ & $2.6(1.4,4.6)^{*}$ & $3.4(1.3,8.9)^{*}$ & $4.2(2.2,8.1)^{*}$ \\
\hline \multicolumn{6}{|l|}{ Home ownership } \\
\hline Does not own & 61.5 & REF & REF & REF & REF \\
\hline Owns alone or jointly & 38.5 & $1.0(0.5,1.9)$ & $0.5(0.3,0.9)^{*}$ & $0.7(0.4,1.6)$ & $0.5(0.3,0.8)^{*}$ \\
\hline \multicolumn{6}{|l|}{ Visited health facility in last $12 \mathrm{~m}$} \\
\hline No & 71.9 & REF & REF & REF & REF \\
\hline Yes & 28.1 & $2(0.9,4.3)$ & $1.9(1.2,2.8)^{*}$ & $1.7(0.7,4.0)$ & $1.6(1,2.7)^{*}$ \\
\hline \multicolumn{6}{|l|}{ Respondent's desire for more children } \\
\hline Wants after $2+$ years & 52.7 & $3.6(0.8,17.2)$ & $2.3(0.9,5.9)$ & - & $4.2(1.2,14.6)^{*}$ \\
\hline Wants, unsure timing & 39.3 & $5.5(1.1,27.6)^{*}$ & $1.7(0.6,4.6)$ & - & $1.2(0.3,5.2)$ \\
\hline Wants no more or can't have more & 8.1 & REF & REF & REF & REF \\
\hline Ideal number of children & 5.3 (mean) & $0.8(0.7,1)^{*}$ & $0.8(0.7,0.9)^{*}$ & $0.7(0.6,0.9)^{*}$ & $0.8(0.7,0.9)^{*}$ \\
\hline Husband's desire for more children & & N/A & & & \\
\hline Both wants same & 17.6 & & & REF & REF \\
\hline Husband wants more & 35.3 & & & $0.2(0.1,0.5)^{*}$ & $0.3(0.2,0.8)^{*}$ \\
\hline Husband wants fewer & 3.1 & & & $0.4(0.1,1.8)$ & $0.5(0.1,3)$ \\
\hline Don't know & 44.0 & & & $0.2(0.1,0.6)^{*}$ & $0.5(0.3,1.1)$ \\
\hline Lifetime sex partners & & & & $N / A$ & \\
\hline 1 partner & 80.7 & REF & REF & & \\
\hline 2 partners & 12.9 & $1.5(0.8,2.7)$ & $1.9(1.1,3.4)^{*}$ & & \\
\hline $3+$ partners & 6.5 & $0.8(0.3,1.9)$ & $2.4(1.2,4.9)^{*}$ & & \\
\hline \multicolumn{6}{|l|}{ Recent sexual activity } \\
\hline Active in the last 4 weeks & 61.6 & $2.3(1.3,3.9)^{*}$ & $1.8(1.2,2.9)^{*}$ & $2.2(0.9,5.7)$ & $1.2(0.7,2.2)$ \\
\hline Not active in last 4 weeks & 38.4 & REF & REF & REF & REF \\
\hline
\end{tabular}

${ }^{\dagger}$ Adjusted for the following variables: religion, getting medical help: not wanting to go alone, number of other wives. N/A variable not included in model. ${ }^{*} p<0.05$

she may have more power in the home and over her reproductive choices. Changing norms to give women more ownership of physical property may translate into empowerment over their own family planning.

Our results indicate that several key indicators may not play a significant role in modern contraceptive use. Access to care variables and knowledge indicators were mostly not associated with contraceptive use. Although some women may be too young to have sought care, these findings reinforce the notion that young women may not use contraceptives because of social norms and familial circumstances that prescribe their reproductive choices. In order to empower women to make their own reproductive choices, we must work to change societal norms that may limit their personal agency. [16]
Since these results are cross-sectional, we are limited in our ability to infer causation and can only attest to associations between contraceptive use and potential indicators. Also, given the rarity of our outcome, the number of covariates we could include in the models was limited to what would allow for convergence. Therefore, we may not have controlled for all possible confounding factors. Regardless of these limitations, our findings are generally consistent with the peer-reviewed literature.

\section{Conclusion}

Young women in Burkina Faso and Mali are increasingly using LAPM and STM contraceptives for family planning. However, these increases are not at the rate needed 
to meet the United Nations' Sustainable Development Goals or to have an impact on the resource-depleting population boom both countries are experiencing. In a society where ideal family size is high and male spousal reproductive preferences are honored, social norms may limit women's choices around family planning and use of modern contraceptives. To increase modern contraceptive use and curb fertility rates, local governments and development organizations should focus on women's empowerment and include male partners, as their preferences matter when women make reproductive choices.

\section{Endnotes}

${ }^{1}$ These results may be impacted by the Mexico city policy and other international and local abortion laws. This was not the focus of this study and the impact of abortion policy should be explored in future research.

\section{Additional files}

Additional file 1: Burkina Faso: Distribution of variables of interest for sexually active women ages 15-24: Trends in the DHS Women's Survey. This document includes a table of frequencies and weighted percentages for all variables of interest in Burkina Faso for the three most recent DHS surveys. (DOCX 35 kb)

Additional file 2: Mali: Distribution of variables of interest for sexually active women ages 15-24: Trends in the DHS Women's Survey. This document includes a table of frequencies and weighted percentages for all variables of interest in Mali for the three most recent DHS surveys. (DOCX $34 \mathrm{~kb}$ )

Additional file 3: Binary outcome analysis. This document includes a description of preliminary significance testing using a binary outcome to limit variables for model inclusion in the multivariate analysis. (DOCX $18 \mathrm{~kb}$ )

\section{Abbreviations}

DHS: Demographic and health survey; IUD: Intra-uterine device; LAPM: Long acting or permanent method; mCPR: Modern contraceptive prevalence rate; SRH: Sexual and Reproductive Health; STM: Short term method; TFR: Total fertility rate

\section{Acknowledgements}

The authors would like to acknowledge Alissa Bernholc, Natasha Mack, Andres Martinez and Annette Brown for reviewing the final manuscript and Kathryn Church and Chelsey Porter for providing feedback during the analysis phase.

\section{Funding}

This research was funded by a sub-award from Marie Stopes International and USAID (AID-OAA-A-14-00036) for improving access to quality, affordable reproductive health and family planning information and services in Burkina Faso, Mali and Niger. Manuscript development and publication funding was provided through a small publication grant from the FHI 360 Research and Evaluation Strategic Initiative.

\section{Availability of data and materials}

The datasets generated analyzed during the current study are available in the DHS repository, www.dhsprogram.com/data/.

\section{Authors' contributions}

$\mathrm{AO}$ analyzed and interpreted all DHS data and was a major contributor in writing the manuscript. GT lead study design and wrote significant portions of the background, discussion and conclusions sections. Both authors read and approved the final manuscript.
Ethics approval and consent to participate

Since this research involved the secondary analysis of deidentified publicly available datasets, and there was no interaction with human subjects, ethics approval was not sought.

\section{Consent for publication \\ N/A}

\section{Competing interests}

The authors declare that they have no competing interests.

\section{Publisher's Note}

Springer Nature remains neutral with regard to jurisdictional claims in published maps and institutional affiliations.

Received: 16 June 2017 Accepted: 13 October 2017

Published online: 03 November 2017

\section{References}

1. May J, Guengant J. Les défis démographiques des pays sahéliens. ÉTVDES. 2014;4206:19-30.

2. World Development Indicators. The World Bank; 2014

3. Cleland J, Conde-Agudelo A, Peterson H, Ross J, Tsui A. Contraception and health. Lancet. 2012:380:149-56.

4. Haider TL, Sharma M. Barriers to family planning and contraception uptake in sub-Saharan Africa: a systematic review. Int Q Community Health Educ. 2012;33:403-13.

5. Ugaz JI, Chatterji M, Gribble JN, Banke K. Is household wealth associated with use of long-acting reversible and permanent methods of contraception? A multi-country analysis. Glob Health Sci Pract. 2016;4:43-54.

6. Ayanore MA, Pavlova M, Groot W. Unmet reproductive health needs among women in some west African countries: a systematic review of outcome measures and determinants. Reprod Health. 2016;13:5.

7. ICF International. Demographic and health surveys (various). Calverton: ICf International [Distributor]; 2012.

8. Heeringa W. Berglund: Applied Sunvey Data Analysis. Boca Raton, FL: CRC Press; 2010.

9. Belsley K. Welsch: Regression Diagnostics: Identifying Influential Dat and Sources of Collinearity. Hoboken, NJ: Wiley and Sons; 2004.

10. SAS Data Analysis Examples Logit Regression [https://stats.idre.ucla.edu/sas/ dae/logit-regression/ ].

11. Trends in Contraceptive Use Worldwide 2015. United Nations, Department of Economic and Social Affairs, population division 2015.

12. UN General Assembly. Transforming our world: the 2030 Agenda for Sustainable Development. 21 October 2015, A/RES/70/1.

13. Chandra-Mouli V, McCarraher DR, Phillips SJ, Williamson NE, Hainsworth G. Contraception for adolescents in low and middle income countries: needs, barriers, and access. Reprod Health. 2014;11:1.

14. Bankole A. Desired fertility and fertility behaviour among the Yoruba of Nigeria: a study of couple preferences and subsequent fertility. Popul Stud. 1995:49:317-28.

15. Bankole A, Ezeh AC. Unmet need for couples: an analytical framework and evaluation with DHS data. Popul Res Policy Rev. 1999;18:579-605.

16. Upadhyay UD, Gipson JD, Withers M, Lewis S, Ciaraldi EJ, Fraser A, Huchko MJ, Prata N. Women's empowerment and fertility: a review of the literature. Soc Sci Med. 2014:115:111-20.

Submit your next manuscript to BioMed Central and we will help you at every step:

- We accept pre-submission inquiries

- Our selector tool helps you to find the most relevant journal

- We provide round the clock customer support

- Convenient online submission

- Thorough peer review

- Inclusion in PubMed and all major indexing services

- Maximum visibility for your research

Submit your manuscript at www.biomedcentral.com/submit
Biomed Central 